\title{
Multiple sensors applied to monitorland subsidence in Central Taiwan
}

\author{
W.-C. Hung ${ }^{1}$, C. Wang ${ }^{2}$, C. Hwang ${ }^{3}$, Y.-A. Chen ${ }^{4}$, H.-C. Chiu ${ }^{4}$, and S.-H. Lin ${ }^{4}$ \\ ${ }^{1}$ General Manager, Green Environmental Engineering Consultant Co. LTD \\ ${ }^{2}$ Deputy General Manager, Green Environmental Engineering Consultant Co. LTD \\ ${ }^{3}$ Department of Civil Engineering, National Chiao Tung University \\ ${ }^{4}$ Green Environmental Engineering Consultant Co. LTD \\ Correspondence to: W.-C. Hung (khung@itrige.com.tw)
}

Published: 12 November 2015

\begin{abstract}
During 1992-2013, pumping of groundwater caused large-scale aquifer-system compaction and land subsidence in the Choshui River Alluvial Fan (CRAF) in Taiwan. The subsidence has already endangered the operation of Taiwan High Speed Rail (THSR). In this paper, we introduce the multiple sensors monitoring system to study the extent of subsidence in CRAF and its mechanism, including GPS (Global Positioning System), PSI (Persistent Scatterer Interferometry), leveling and multi-layer compaction monitoring well. These sensors complement each other in spatial and temporal resolutions.
\end{abstract}

\section{Introduction}

Due to continuous growth of the population and economy, more water resources are needed. The use of the underground water is inevitable when the surface water sources become insufficient. Inappropriate excessive exploitation of the underground water may result in land subsidence, which leads to land sinking and other disasters such as long-term water logging. The ocean water invades the water-bearing stratum and results in soil salinization. The utilization value of the soil may be degraded, and it will be difficult to introduce industries and the vital functions are downgraded. The underground water resources will no longer be utilized. These problems will result in the increase of the social cost. The above cases can be found in Table 1 .

Taiwan is located in the subtropical monsoon region, and the climate of Taiwan is oceanic tropical and subtropical. The rainfall is plentiful; the annual rainfall reaches up to $2500 \mathrm{~mm}, 2.5$ times the average world rainfall. However, Taiwan is a country suffering from severe dehydration due to various reasons. Taiwan is also highly populated. On this island, mountains are high and torrents are swift; therefore, most of the rainfall rapidly flows into the ocean. Taiwan strives for high economic development and the total water consumption rises continuously. As a result, underground water has become a major water source. Excessive exploitation of the underground water is common in the country areas. Therefore, critical land subsidence has occurred in the southwestern coastal areas, especially Choushui River Alluvial Fan (CRAF) in recent years.

CRAF is the most important agricultural area in western, central Taiwan, with elevations ranging from 0 to $100 \mathrm{~m}$. CRAF covers a total area of $2000 \mathrm{~km}^{2}$ and is bounded by Wu River (north), Pekang Creek (south), Douliu Mound (east) and Taiwan Strait (west). Figure 1 shows the geographical location of CRAF, which is centered at $24^{\circ} \mathrm{N}$ and $120.5^{\circ} \mathrm{E}$.

Choshui River is the longest river in Taiwan. The sediments in CRAF originate from rock formations in the upstream watershed of Choshui River, including slate, metamorphic quartzite, shale, sandstone, and mudstone (Fig. 2). Sediment loads composed of weathered rock fragments of different sizes gradually settled on the riverbed, floodplain, and seabed to form CRAF. The head of CRAF contains mainly gravel and coarse sand, and the toe is a delta covered by fine sand. Because the upstream watershed area of Choshui River is wide and infiltrative, surface water in the head of the fan will penetrate the ground to recharge the subsurface aquifers. 
Table 1. A list of world countries experiencing subsidence problems.

\begin{tabular}{llll}
\hline Area & Maxima cumulative subsidence $(\mathrm{m})$ & Period & Reference \\
\hline China & 3.0 & $1921-2006$ & Gong and Yang (2008) \\
Mexico & 10 & $2007-2011$ & Chaussard et al. (2014) \\
Spain & 0.15 & $1993-2007$ & Tomás et al. (2010) \\
Taiwan & 0.14 & $2006-2008$ & Hung et al. (2011) \\
CA, US & 9 & $1925-1977$ & Galloway and Sneed (2013) \\
Australia & 0.35 & $2006-2011$ & Ng et al. (2015) \\
Italy & 0.5 & $1897-1937$ & Tosi et al. (2007) \\
Japan & 0.4 & $2011-2014$ & ElGharbawi and Tamura (2014) \\
\hline
\end{tabular}

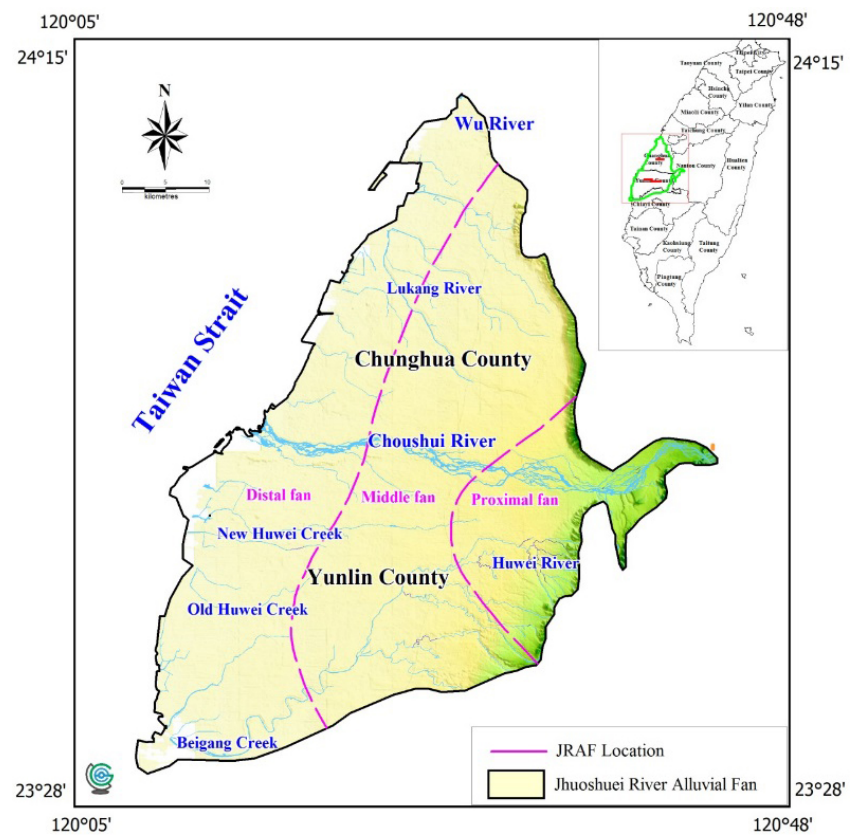

Figure 1. Geographical location of Choushui River Alluvial Fan (CRAF).

Due to the lack of surface water and the flat terrain that prohibits dam construction, the water for civilian and agricultural use in CRAF comes largely from underground. According to the statistics of Water Resource Agency of Taiwan, the extracted groundwater in Yunlin is 94 metric tons a day, totaling 305 million tons a year. Withdrawing groundwater without recharge here will decrease the water level and consequently reduce the porous pressure and increase the effective stress, inevitably leading to land subsidence. The Taiwan High Speed Rail (THSR) passes through Yunlin, where subsidence poses a serious threat to its operation (Hung et al., 2011).

\section{Synergy of monitoring sensors}

In order to further investigate the mechanism of land subsidence, the multi-sensors monitoring system including In-

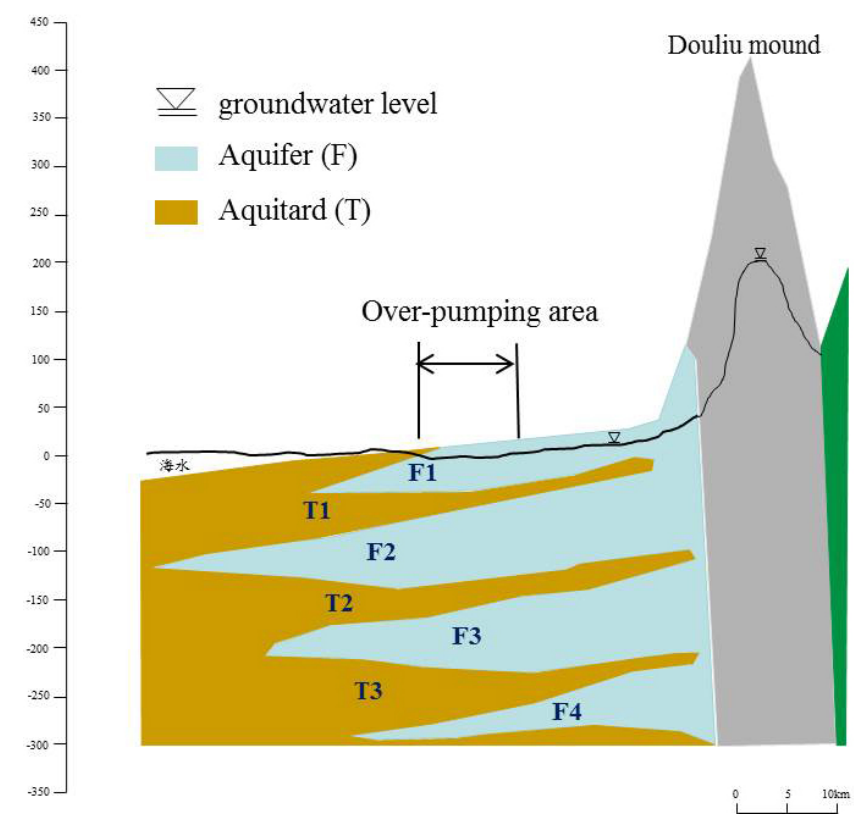

Figure 2. Geological settings of Choshui River Alluvial Fan (modified from Central Geological Survey of Taiwan, http://www. moeacgs.gov.tw/).

SAR, GPS, leveling, multi-layer compaction monitoring well and Piezometer are used to monitor land subsidence in CRAF. Figure 3 is the sample picture of the multi-sensor monitoring system.

Figure 4 shows the distributions of leveling networks, Continuously Operating Reference Stations (CORS) and multi-layer compaction monitoring well used in this paper.

Table 2 summarizes the resolutions and accuracies of these sensors. With these sensors, we may inter-compare different results and complement each other in the spatial and temporal resolutions. With a good spatial correlation and proper environmental corrections, TCPInSAR with ALOS-PALSAR images will deliver areal displacements accurate to few $\mathrm{cm}$ with a $25 \mathrm{~m}$ spatial resolution at a time scale equivalent to the satellite repeat period. At a continuous GPS station, the accuracy of vertical changes can be determined to $1 \mathrm{~cm}$ on a daily 


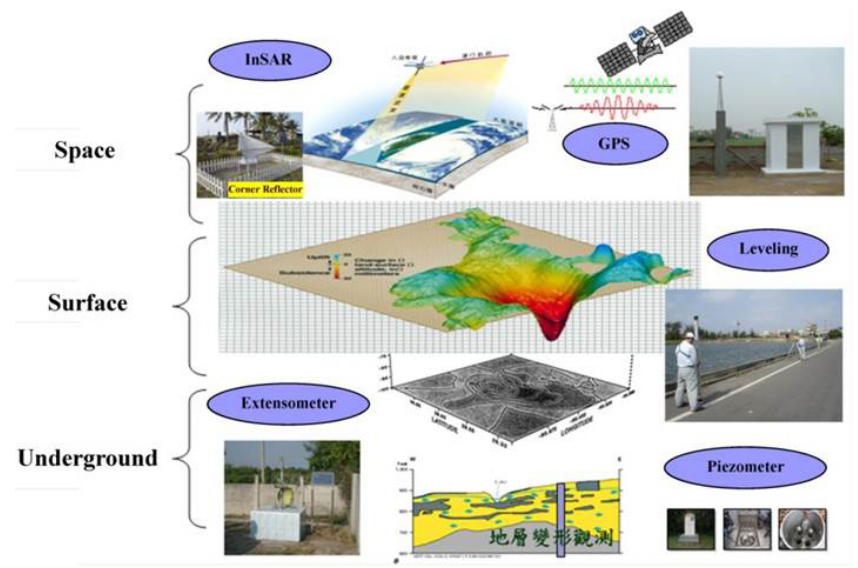

Figure 3. Sample pictures of Multi-sensor monitoring system.

solution. With a precision level and good correction models, leveling can deliver point-wise vertical displacements accurate to few $\mathrm{mm}$ along leveling routes.

In this study, the leveling and INSAR results used to detect the land subsidence area and calculate land subsidence rate in CRAF. In the subsidence center, the Continuously Operating Reference Stations (CORS) and multi-layer compaction monitoring well are used to analyze the mechanism of land subsidence.

\section{Monitoring Result of CRAF}

\subsection{Leveling}

In addition to the THSR leveling network, a leveling network west of THSR was established by Water Resource Agency (WRA) of Taiwan to monitor surface subsidence in Yunlin County.

The length of the leveling network in CRAF is $830 \mathrm{~km}$. The accuracy requirement for the leveling is a $3 \sqrt{K} \mathrm{~mm}$ misclosure in any double run, where $\mathrm{K}$ is the distance between two neighboring benchmarks in $\mathrm{km}$. At each leveling setup, the distances to the foresight and backsight were measured by an electronic distance measurement (EDM) device to ensure the two are identical. Corrections for collimation error, atmospheric refraction and the earth's curvature were applied to the differential heights (Wolf and Ghilani, 2005). Because the cumulative differences between foresight and backsight distances do not exceed $10 \mathrm{~m}$, residual collimation errors, the earth's curvature and atmospheric effects were negligible.

The corrected height differences from leveling were leastsquares adjusted to determine the heights. To ensure the quality of least-squares solution, we screen the observables for outliers using Baada's data snooping technique (Koch, 1987; Caspary, 1988). First the standardized residual of an observ-

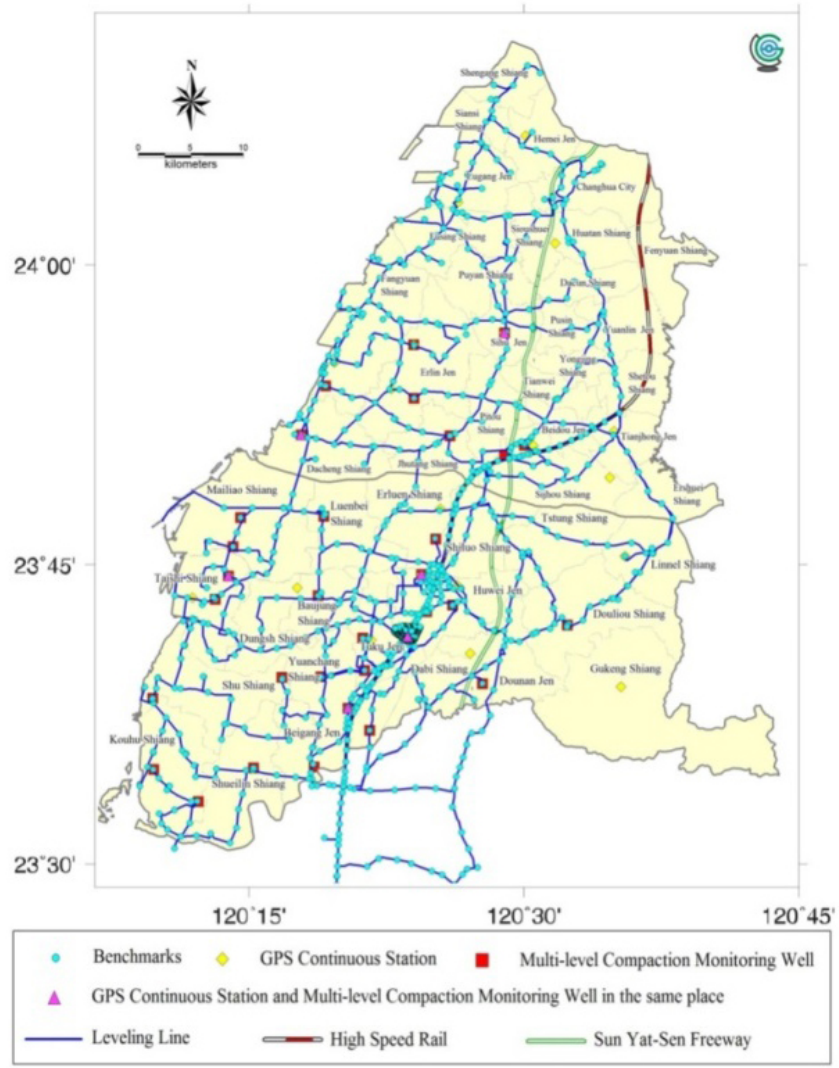

Figure 4. Distributions of leveling benchmarks, monitoring wells and GPS stations in CRAF, the names of townships in Yunlin County and Changhua County are shown here.

able is computed as

$W_{i}=\frac{V_{i}}{\delta V_{i}}$,

where $\delta V_{i}$ is the standard error of residual $V_{i}$, which is the squared root of a diagonal element of matrix $\mathbf{Q}_{v}$ as follows

$\mathbf{Q}_{v}=P^{-1}-A\left(A^{T} P A\right)^{-1} A^{T}$.

With a significance level of 0.01 , the critical value for data snooping in (4) is 3.3. That is, if $W_{i}>3.3$, the observable (height difference) associated with $V_{i}$ is regarded as an outlier and is removed from the input to the adjustment. A second adjustment is then performed without these outliers. Because all misclosures are smaller than $3 \sqrt{K} \mathrm{~mm}$ and all raw data are carefully inspected, we did not find any outliers in the data from the three campaigns.

The cumulate subsidence is defined as change of height in 1992-2003. Contours of subsidence are computed using Kriging and are shown in Fig. 5. In the past two decades, the maximum cumulative subsidence is over $150 \mathrm{~cm}$ and shows a basin-like subsidence pattern centering at Huwei, Tuku, and Yuanchang Township. The serious subsidence are in central Youlin County, i.e. Tuku, Huwei and Yuanchang township. 
Table 2. Multi-sensor comparison table.

\begin{tabular}{lllll}
\hline & Leveling & Continuous GPS & Monitoring Well & InSAR \\
\hline Spatial Resolution & $1.5-2 \mathrm{~km}$ & $10-15 \mathrm{~km}$ & $5-10 \mathrm{~km}$ & $25 \mathrm{~m}$ \\
Survey frequency & 1 year & 1 day & 1 month & 35 day $(\mathrm{C}$ band $)$ \\
Vertical Accuracy & $0.5-1 \mathrm{~cm}$ & $0.5-1 \mathrm{~cm}$ & $0.1-0.5 \mathrm{~cm}$ & $0.5-1 \mathrm{~cm}$ \\
\hline
\end{tabular}

THSR passes through series subsidence area, and land subsidence will result in a major safety concern.

\subsection{Continuously operating reference stations}

The used GPS network, presented in Fig. 6a, in this study consists of 36 GPS stations belong to the governmental agencies in Taiwan including Water Resource Agency (WRA), Central Geological Survey (CGS), Ministry of Interior (MOI), Central Weather Bureau (CWB), and Industry Technology Research Institute (ITRI). The Bernese V5.0 developed by Bern University was adopted to obtain the change of horizontal and vertical coordinates via the automatic data processing strategy. In addition to the used Continuously Operating Reference Stations (CORS), the non-continuously campaign GPS surveying with the fixed-centering, fixedleveling, and fixed-heighting GPS Monumentation (Patent Number: 182781) was also utilized in this investigation on the observation of land surface change. The GPS pilar has been conformed to National Geodetic Survey (NGS), which indicate the fixed-centering, fixed-leveling, and fixedheighting are necessary for the campaign GPS surveying with $2 \mathrm{~cm}$ accuracy campaign (Zilkoski et al., 1997).

According to the results from the GPS CORSs observed from April 2010 to April 2014, presented in Fig. 6b, the region along the high speed rail runs through the main subsidence area in the Yunlin County, especially around the Huwei Township (GFES GPS station located), Tuku Township (TKJS GPS station located), and Yuanchang Township (KTES GPS station located). The rate of subsidence can reach $6 \mathrm{~cm}$ per year. The agreement between the results from GPS CORS and Leveling survey can be obtained. Because the advantage of continually observing from GPS CORS, the deformation of land surface caused by the seasonal variation and the change of groundwater in wet/dry season can be detected via the Principal Component Analysis (PCA) strategy.

\subsection{Multi-layer compaction monitoring well}

As mentioned previously, the subsurface deposits constituted the aquifer system in CRAF are not only heterogeneous but also with different hydraulic and mechanical properties in each layer. In order to well understand the mechanism of subsidence, the multi-layer compaction monitoring well technique is applied to measure compaction at different stratigraphic intervals within the aquifer system (Fig. 7).
The basic principle of multi-layer compaction monitoring well is to measure the depths of magnetic rings precisely and to analyze the depth differences of all the rings. The depth difference of two adjacent rings indicates the deformation of the stratigraphic section between the two rings. Hence the compaction amount of each layer to the total subsidence can be determined. In general, 20 to 26 magnetic rings are anchored in each well based on the different stratigraphic types, and the depths of the rings are measured at a one-month interval. Moreover, the advantage of multi-layer compaction monitoring well is the capability of monitoring multi-layer compaction with high accuracy (about $1 \mathrm{~mm}$ ) and stability (Hung et al., 2012). Currently there are 31 multi-layer compaction monitoring wells installed in CRAF (Fig. 4).

Figure 8 shows the cumulative compactions at the TKJS monitoring well which is located at the most serious subsidence area along the rail of THSR from 2004 to 2011. As the result of the aquifer system which contains highly compressible alternations of sand and clay, the majority and the secondary compaction occur at depths deeper than $200 \mathrm{~m}$ and 50 to $200 \mathrm{~m}$, respectively. Moreover, based on the compactions at different strata, the monitoring well result can illuminate the main source of water pumping as well. For example, if the major compaction occurs at a deeper stratum, the municipal and industrial water are the main sources of water use. On the contrary, if the major compaction occurs at a shallow stratum, the agricultural water is the main source of water use. Therefore, the compaction monitoring well is not only to understand the strain source effectively but also to mitigate the land subsidence problem usefully.

\subsection{Areal subsidence by multi temporal InSAR, MT-InSAR}

In the past decades, synthetic aperture radar interferometry (InSAR) has been proved to be a powerful and effective geodetic technique, with high spatial resolution, subcentimeter accuracy and useful observation cadence, for measuring surface deformation. Nevertheless, due to the different surface features with time and the variation of water vapor stratification between satellite passes would easily cause spatial decorrelation in conventional SAR interferometry, and lead to a degraded accuracy in the deformation measurements. Thus, the multi-temporal InSAR (MTInSAR) techniques are developed to overcome the limitation of DInSAR technology. Currently, there are three categories 


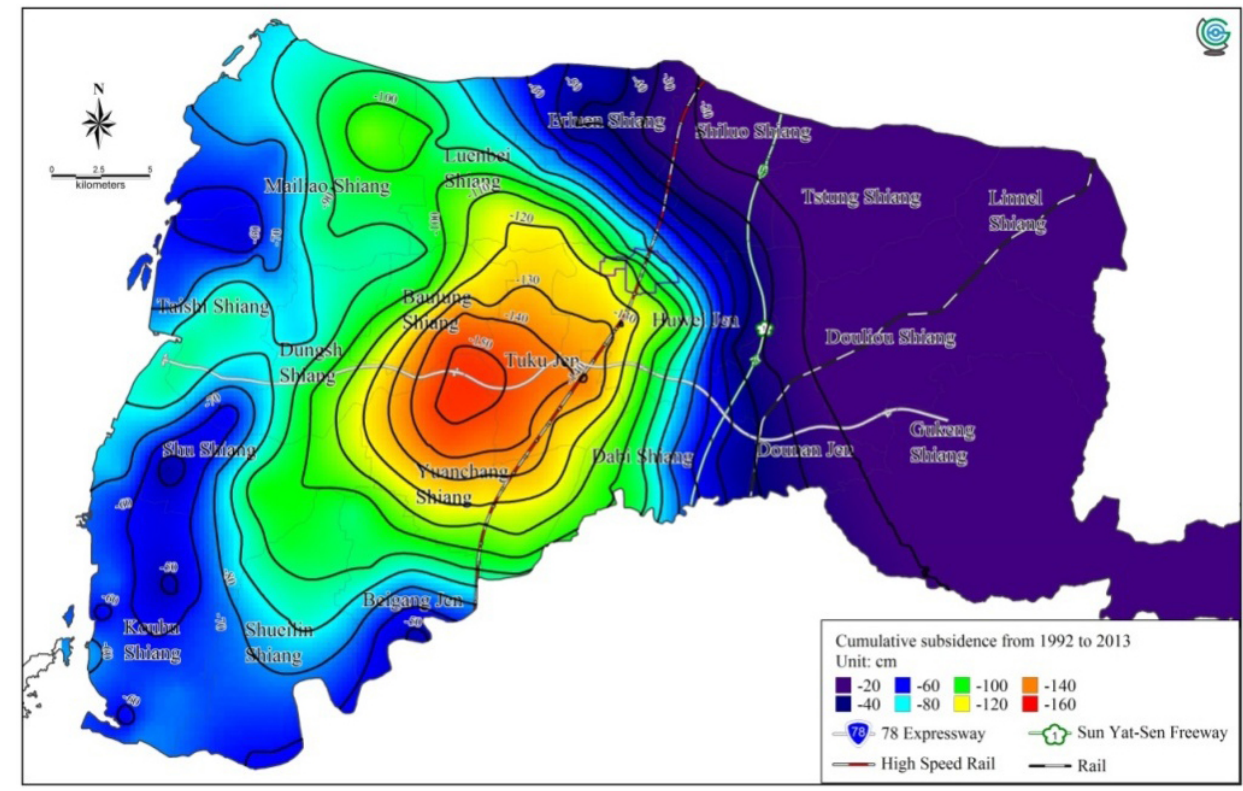

Figure 5. Cumulative subsidence derive from leveling over 1992-2013.

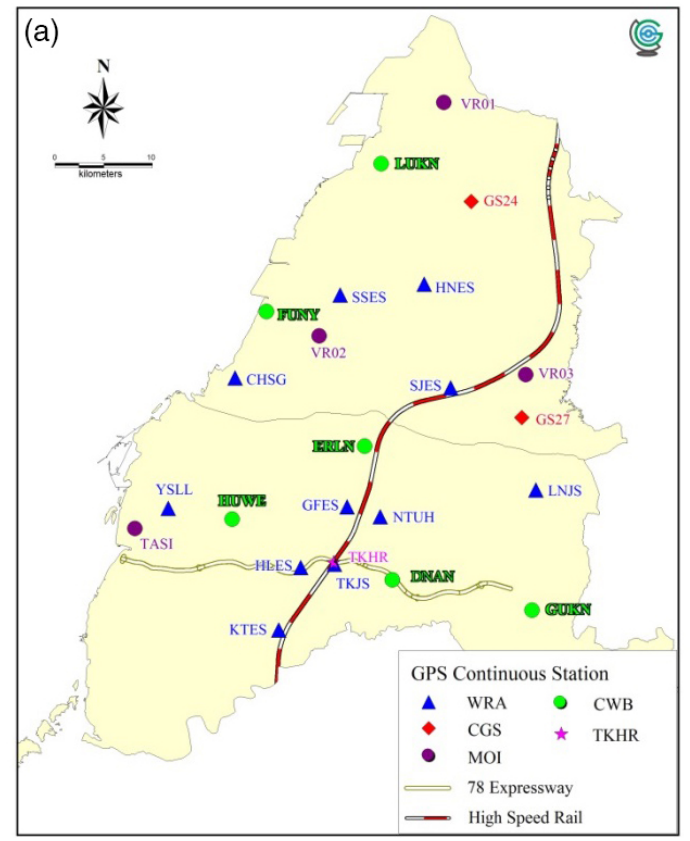

(b)

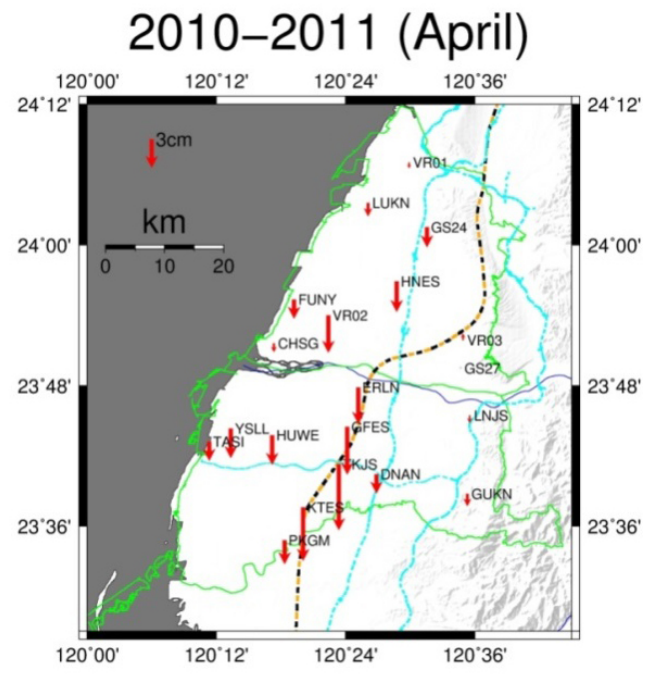

GMD 2014 Jul 2805:27:36 plot by GEEC

Figure 6. (a) Distributions of continuous GPS stations in CRAF (b) Vertical displacement rate from GPS over April 2010-April 2011.

of MT-InSAR approaches used to monitor land subsidence in Taiwan, such as persistent scatterersInSAR (PSI) (Hooper et al., 2004), Stanford method for persistent scatterers/multitemporal InSAR (StaMPS/MTI) (Hooper, 2008) and temporarily coherence point InSAR (TCPInSAR) (Zhang et al., 2011).

In this study, we utilize TCPInSAR approach to measure the ground deformation in CRAF from 2007 to 2011 and to compare the TCPInSAR result with precise leveling data. From the comparison result, the TCP pixel density over CRAF is 346 pixels $\mathrm{km}^{-2}$ which is much higher than the leveling benchmarks $\left(0.2\right.$ points $\left.\mathrm{km}^{-2}\right)$. Moreover, the vertical displacements inferred from TCPInSAR show good consistency with the leveling result to $10 \mathrm{~mm}$ year $^{-1}$ (RMS), and provides a higher spatial resolution of subsidence than the latter. Besides, we also develop a data fusion method that considers the high-precision leveling data as a smoothed correction to the PSI measurement (Hung et al., 2011). Figure 9 

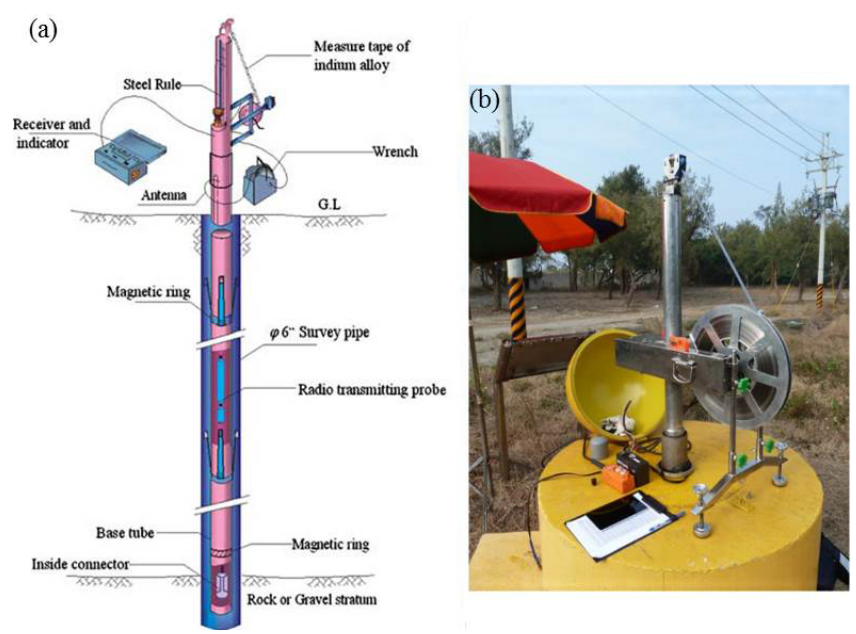

Figure 7. Sample pictures of multi-layer compaction monitoring well.
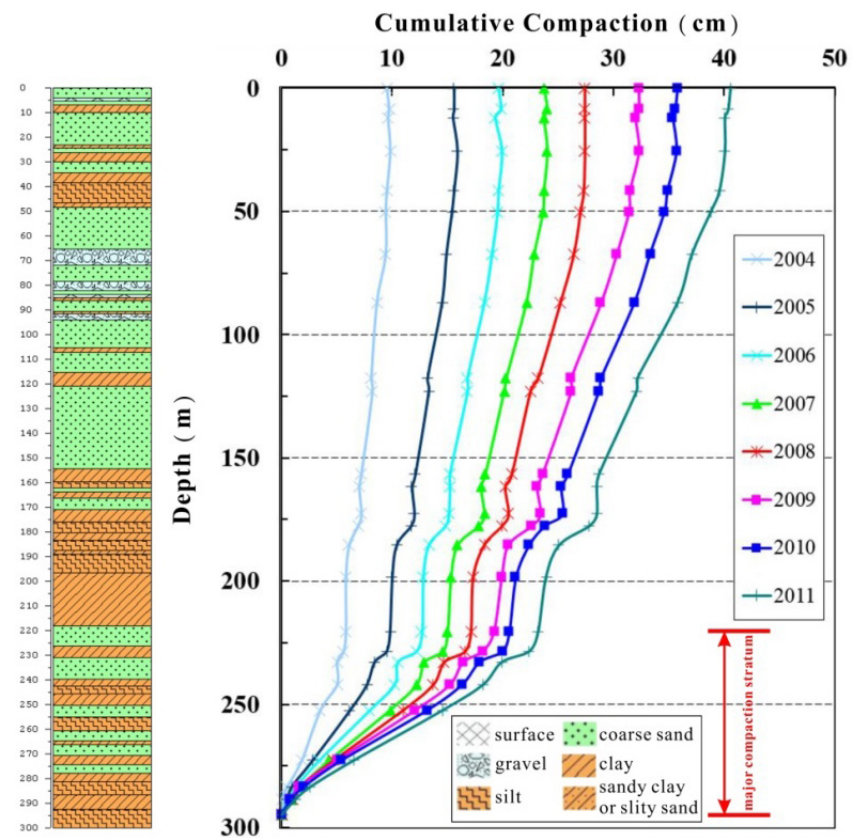

Figure 8. Layers of sediments and cumulative compactions from 2004 to 2011 at TKJS.

shows the vertical displacement rate after data fusion processing during the period between 2007 and 2011 in CRAF, and the deformation pattern is quite consistent with the leveling result. The major subsidence areas in CRAF are located in western areas of Sun Yat-Sen Freeway, e.g. middle fan and distal fan areas (see Fig. 1). The combined displacement field is more representative of overall deformation characteristics than the TCPInSAR-only or leveling-only field, and it is better suited for the assessment of the impact of subsidence over CRAF.

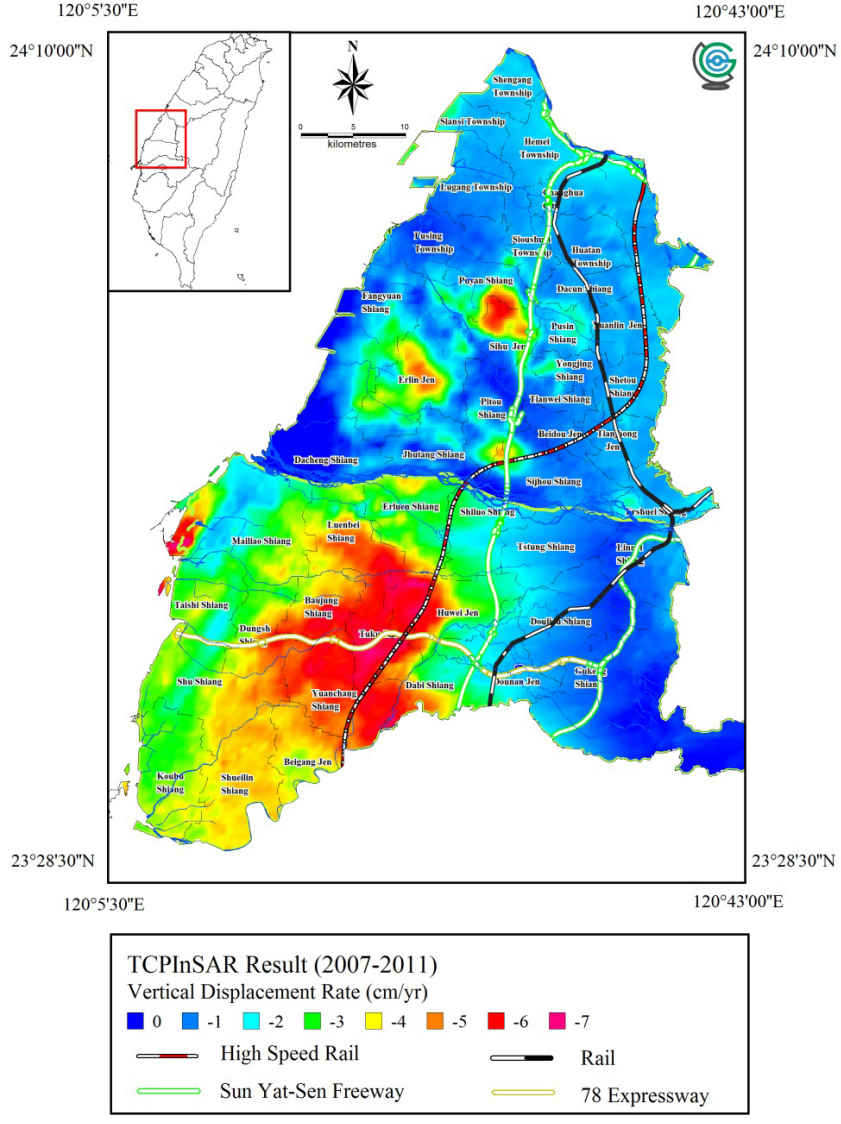

Figure 9. Vertical displacement rate from TCPINSAR over 20072011.

\section{Discussion and conclusions}

The security of country's territory has been affected by the long term land subsidence. The multi-sensors system developed by Taiwanese government including GPS, PSI, Leveling, monitoring well, and groundwater well can monitor the land subsidence from space, ground, and underground. Not only does it control the deformation of land surface efficiently and understand the magnitude and major source of stress for the shallow and deeper land, but also goes with policy of industry. The rate and area of land subsidence can be reduced efficiently. In the future, monitoring action will be conducted by extending the area and executing automatically. 400 GPS CORSs around Taiwan will be included for the understanding of the variation of three dimensions. Meanwhile, combining with airborne PSI, GPS, and data fusion technology, the affected range and change of land subsidence can be controlled quickly and precisely.

Acknowledgements. This study is supported by Water Resource Agency, Dept. of Economics, Taiwan, R.O.C. 


\section{References}

Caspary, W. F.: Concepts of Network Adjustment and Deformation Analysis. Monograph 11, Scholl of Surveying, University of New South Wales, Kensington, NSW, Australia, 183, 1988.

Chaussard, E., Wdowinski, S., Cabral-Cano, E., and Amelung, F.: Land subsidence in central Mexico detected by ALOS InSAR time-series, Remote Sens. Environ., 140, 94-106, 2014.

El Gharbawi, T. and Tamura, M.: Measuring deformations using SAR interferometry and GPS observables with geodetic accuracy: Application to Tokyo, Japan, ISPRS J. Photogramm. Remote Sens., 88, 156-165, 2014.

Galloway, D. L. and Sneed, M.: Analysis and simulation of regional subsidence accompanying groundwater abstraction and compaction of susceptible aquifer systems in the USA, Bol. Soc. Geol. Mex., 65, 123-134, 2013.

Gong, S. L. and Yang, S. L.: Effect of land subsidence on urban flood prevention engineering in Shanghai, The Key Magazine of China Technology, 39, 1-20, 2008.

Koch, K. R.: Parameter Estimation and Hypothesis Testing in Linear Models, Springer, Berlin, 378, 1987.

Hooper, A.: A multitemporal InSAR method incorporating both persistent scatterer and small baseline approaches, Geophys. Res. Lett., 35, 2008.

Hooper, A., Zebker, H., Segall, P., and Kampes, B.: A new method for measuring deformation on volcanoes and other natural terrains using InSAR persistent scatterers, Geophys. Res. Lett., 31, 2004.
Hung, W.-C., Hwang, C., Chen, Y.-A., Chang, C.-P., Yen, J.-Y., Hooper, A., and Yang, C.-Y.: Surface deformation from persistent scatterers SAR interferometry and fusion with leveling data: A case study over the Choushui River Alluvial Fan, Taiwan, Remote Sens. Environ., 115, 957-967, 2011.

Hung, W.-C., Hwang, C., Liou, J.-C., Lin, Y.-S., and Yang, H.-L.: Modeling aquifer-system compaction and predicting land subsidence in central Taiwan, Eng. Geol., 147, 78-90, 2012.

$\mathrm{Ng}$, A. H. M., Ge, L., and Li, X.: Assessments of land subsidence in the Gippsland Basin of Australia using ALOS PALSAR data, Remote Sens. Environ., 159, 86-101, 2015.

Tosi, L., Teatini, P., Carbognin, L., and Frankenfield, J.: A new project to monitor land subsidence in the northern Venice coastland (Italy), Environ. Geol., 52, 889-898, 2007.

Tomás, R., Herrera, G., Delgado, J., Lopez-Sanchez, J. M., Mallorquí, J. J., and Mulas, J.: A ground subsidence study based on DInSAR data: Calibration of soil parameters and subsidence prediction in Murcia City (Spain), Environ. Geol., 111, 19-30, 2010.

Wolf, P. R. and Ghilani, C. D.: Elementary surveying: an introduction to geomatics, Pearson Prentice Hall, 2005.

Zhang, L., Ding, X., and Lu, Z.: Ground settlement monitoring based on temporarily coherent points between two SAR acquisitions, ISPRS J. Photogram. Remote Sens., 66, 146-152, 2011.

Zilkoski, D. B., D’Onofrio, J. D., and Frakes, S. J.: Guidelines for Establishing GPS-derived Ellipsoid Heights (standards, $2 \mathrm{Cm}$ and $5 \mathrm{Cm}$ ), Version 4.3: US Department of Commerce, National Oceanic and Atmospheric Administration, National Ocean Service, National Geodetic Survey, 1997. 